\title{
GREEK IN UKRAINE: RESULTS OF WORK AND PROSPECTS FOR THE DEVELOPMENT OF THE GREEK PHILOLOGY AND TRANSLATION DEPARTMENT AT MARIUPOL STATE UNIVERSITY
}

\author{
Arhiris Nicas \\ philologist sent to Ukraine by the Ministry of Education of Greece \\ Department of Greek Philology and Translation \\ Mariupol State University \\ 129a, Budivelnykiv Ave., Mariupol 87500, Ukraine \\ gph@mdu.in.ua \\ Efi Macri \\ philologist sent to Ukraine by the Ministry of Education of Greece \\ Department of Greek Philology and Translation \\ Mariupol State University \\ 129a, Budivelnykiv Ave., Mariupol 87500, Ukraine \\ gph@mdu.in.ua
}

\section{ABSTRACT}

The Department of Greek Philology and Translation of Mariupol State University, which celebrates its 20th anniversary this year, functions as the main carrier of teaching, dissemination and spreading of the Greek language and Greek culture, not only for the Ukrainian people, but also for representatives of the Greek Diaspora in the country and, in particular, in the Azov Sea region. The article illustrates the results of the work of the Department of Greek Philology and Translation of Mariupol State University.

Key words: Department of Greek Philology and Translation; Greek language; Greek culture.

\section{INTRODUCTION}

The Department of Greek Philology and Translation operates philological and translation programs and provides an opportunity to obtain the second specialization in philology, translation of the second foreign language - usually English, as well as the opportunity to deepen the research skills at the educational level of the "Master".

The main goal, in addition to studying the Greek language, is to provide the necessary theoretical training to achieve understanding at the highest scientific level of the structure and functioning of the modern Greek language as a semiotic system of theoretical, applied and contrastive linguistics that seeks the meaning of linguistic and non-linguistic sign systems. Particular attention is also paid to the formation of analytical and contrastive thinking in studies related to the Greek language, literature, history and culture. Multifaceted scientific activity is concentrated especially on research in the field of general and classical philology, pedagogical research, methods of teaching Greek as a foreign language, etc. 
The purpose of the article is to analyze the results of the work of the Department of Greek Philology and Translation of Mariupol State University and to determine the prospects for its development.

\section{DEPARTMENT OF GREEK PHILOLOGY AND TRANSLATION: RESULTS OF WORK}

Thanks to various research programs (for example, the program of the Institute of the Greek Diaspora in Ukraine located at the university), whose goal is a multifaceted study of the Greek diaspora in the Black Sea countries, the emphasis is made on the study of cultural elements, in particular of the language of the Greeks of the Azov Sea region, that is, the Rume ka and Urum dialects.

In addition, in cooperation with the Mariupol Society of Greeks and the Federation of Greek Societies of Ukraine based in the city, the Department of Greek Philology and Translation organizes numerous events such as theater productions, contests, dances, lectures, invitations of various guests from Greece and other countries that directly respond Greek themes. Thus, it strengthens the self-awareness of local Greeks, promotes both the spread of Hellenism, and the strengthening of friendship and cooperation of Ukraine with our national centers in Greece and Cyprus.

In addition, the department in cooperation with the Federation of Greek Societies of Ukraine, the Consulate General of Greece, the Consulate of the Republic of Cyprus, where the post of honorary consul is occupied by K. Balabanov, the rector of the university with the financial support of Greek entrepreneurs, organizes the All-Ukrainian Olympiad on the Greek language, history and culture of Greece and Greeks of Ukraine. This fact has a huge national importance, it is crucial in the study and preservation of the Greek language and cultural heritage of the region, since the interest that is noted is great.

Mariupol State University and other organizations share a passion for the Greek language and everything that concerns Greece. Through the language, they also propagate Greek culture, when they pass this passion to the new generation, supporting their expectations of an optimistic future for Greek studies outside of Greece, their ambitious and desired goal is to make the Greek language the first foreign language to be chosen at will, but not forcibly. Moreover, it deserves this, because universal and eternal notions and values of the world civilization, acknowledged by everyone, are declared in it.

It should be noted that the desire to participate in the above actions and events, the enthusiasm of the participants is especially intense for all people of Greek origin but not only for them, because it is important not only for Greek society but for the whole Azov Sea region and this is covered in mass media.

The graduates of the Department of Greek Philology and Translation are given the opportunity, first of all, to work as teachers of the Greek language in schools of Ukraine, where Greek is taught as a foreign language, as translators in various organizations and institutions, in public institutions, in the media, in the diplomatic sphere, or to continue their studies in Greece and in other countries.

The Greek state on the other hand, understanding the diverse needs of supporting the Greek-language education abroad, which it considers to be obvious, and recognizing the work of those who labour for it, supports them in various ways. For example, it provides free online access to books and digital educational 
material, grants and awards to pupils and students of Greek origin or not who have excellent achievements in the study of the Greek language and who are highly active in its dissemination and training. In addition, it often directs teachers from the National and Kapodistrian University of Athens, from the Aristotle University of Thessaloniki for various training seminars on methodology for future MSU teachers. What else is most important is that the Greek state sends teachers from Greece - philologists and teachers, as the authors of this article - who contribute to the work for at least three years.

It is especially important to note the great contribution of the Republic of Cyprus, which assists in various ways and programs, such as the training and reception of Ukrainian students and teachers at the University of Cyprus, scholarships for postgraduate students, provision of teaching aids and equipment, money prizes and books, for example, the creation of the Modern Greek library rich in books of Kostantinos Levendis Foundation.

The great, constant goal is getting by schoolchildren and students of the Greek diaspora of the necessary knowledge and skills for acquiring, preserving and emphasizing of a special linguistic and cultural identity, for all-round development of their personality, while promoting mutual understanding, peaceful coexistence and development of cooperation between the countries. The ultimate goal is to create a worldwide network of Greek education through the use of new digital technologies.

\section{SUGGESTIONS}

The problems and criticism of educational systems was and is a timeless risk at the worldwide level. This is because the educational systems and the learning process themselves consist of many factors, performers and organizations.

We could offer a lot to optimize educational and research work, to evaluate the results of the learning process in connection with certain goals in a particular educational institution.

One of these proposals can be the corresponding didactic and pedagogical use of information and communication technologies (ICT) in pedagogical practice.

Higher education, in spite of the fact that it differs in age data, target, special knowledge, tasks of those who teach, their maturity and, in general, the structure, also represents a great similarity with the educational system of the secondary education. In other words, adult education, despite being different from the education of children, has much in common.

Effective integration of ICT in the educational process of the Department of Greek Philology and Translation can be a turning point in its educational policy. This is because it is generally accepted that the widespread use of ICT in developed countries is accompanied by optimistic conclusions about their contribution to improving the learning process and improving the quality of education. Through individual tools, that is, computers, software, interactive systems, networks, telecommunications services, and their pedagogical use based on modern learning theories with an emphasis on the ability to cooperate, ICTs radically change the type of education.

"If a child cannot learn, when we teach in a certain way, we must teach so that she can study," writes Maria Montessori. That is, the point of view of the wellknown Italian teacher is not essentially different from the slogan that represents 
ICT "A pupil must learn how to learn". It does not differ even from the statement: "The mind of a child is not a container for filling only with knowledge, but a match that waits for you to light it", which is supported by Plutarch, the great Greek historian, biographer and writer of antiquity.

Within this framework, support for teaching and learning with the help of ICT functions, that is, teaching that mediates through software applications and other digital technologies, cultivates information literacy, satisfying the prerequisites for the realization of the "knowledge society". "New technologies enrich the educational process with unlimited sources of educational materials and interactive information systems, improving the quality of teaching and the learning process. Scientific research confirms the growing number of studies and developments that show that ICTs activate students' attention and thinking, multiply the possibilities of recalling information, offering the opportunity for a meaningful interpretation and understanding of these phenomena. In addition, a significant number of studies confirm the positive impact of ICT on understanding the basic concepts of cognitive objects, such as, for example, the language. The use of modern teaching aids significantly contributes to the development of higher cognitive skills by creating new conditions for building new knowledge by the students themselves, focusing attention, stimulating interest, increasing student participation through self-motivation of the activity, active content distribution, experimentation and interaction."

The strategies for ICT integration in education and their pedagogical use are carried out within the framework of an organized and structured form of training, which is reflected in the "teaching scenarios", which are mainly developed in accordance with the principles of constructive and socially-cognitive approaches to learning, where the student occupies a central place, interacts with teachers.

Within the framework of the "Teaching Scenarios", the use of ICTs is integrated into activities that promote the development of the ability to teamwork, dedication, active participation of teachers, through interactive activities, including action reverse action, research, problem solving, formulation of conclusions, creativity and innovation in order to improve the quality of training.

But all this requires appropriate training of teachers, to determine their role in the implementation of new educational and pedagogical practices.

"The mediocre teacher says. A good teacher explains. The best teacher shows. A great teacher inspires," says William Arthur Ward, an American writer.

In order for this teacher to really inspire, the use of ICT is required in the teaching process, which really demonstrates this new role. On the basis of which the teacher works more as a dispatcher of the cognitive process, as an intermediary, as a mentor and creator of personalities, capable of constant adapting, and learning how to learn genuinely and efficiently.

The promotion of this new role of the teacher is directly related to the prevention or significant reduction of the classical teaching model or the use of more "flexible" teaching methods such as general, exploratory and cognitive learning supported by educational programs and Internet services in the framework of the "Teaching Scenarios". 


\section{CONCLUSIONS}

Teachers, in order to be able to meet the modern requirements of serious work that is carried out in universities or schools, cannot be content with the knowledge acquired only during their training, which in many cases was obtained before the wide dissemination of new technologies in our lives and, in particular, in educational process. Therefore, it is extremely necessary to update one's knowledge at all times or at least at regular intervals, to be aware of the development of pedagogical sciences and the didactic and pedagogical use of information technologies, thus updating one's cognitive base, significantly contributing to the modernization of training concepts and strategies of teaching method renewal.

In addition, relevant studies in international scientific literature and the Internet space clearly demonstrate, by identifying training needs through a specific methodology (for example, interviews or filling in the relevant individual questionnaires), the extreme need for a comprehensive program through a continuous and systematic training model for improving and modernization of education and research work.

Everybody hopes that the procedures for the implementation of these programs and tasks will begin in the near future, with the help of all those who can contribute to this work, especially Greece and Cyprus, by signing interstate and interuniversity agreements with Ukraine and the University.

\section{REFERENCES}

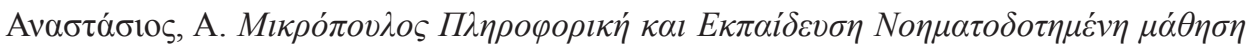

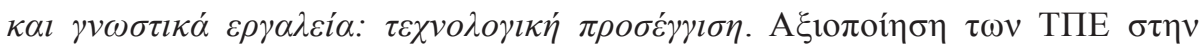
$\varepsilon \kappa \pi \alpha i ́ \delta \varepsilon v \sigma \eta$ [Electronic resource]. Retrieved from http://tinyurl.com/n216bs4

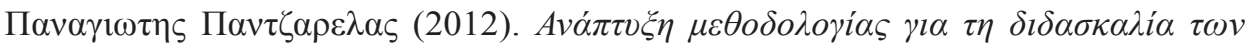

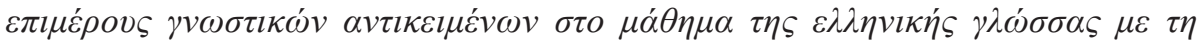

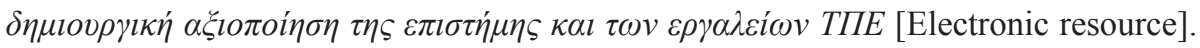

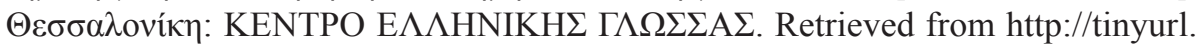
com/hu3a9fj 